\title{
The Epidemiology of Persons Living with Fontan in 2020 and Projections for 2030: Development of an Epidemiology Model Providing Multinational Estimates
}

Leandra Plappert · Susan Edwards · Assunta Senatore •

Angela De Martini

Received: October 6, 2021 / Accepted: November 16, 2021 / Published online: December 22, 2021

(c) The Author(s) 2021

\section{ABSTRACT}

Introduction: Fontan surgery is a palliative procedure performed in children with a functionally univentricular heart. Improvements in surgical technique over the past 30 years have increased life expectancy in this rare population. However, the epidemiology of persons living with Fontan is poorly understood. This study aimed to estimate the 2020 and 2030 prevalence of persons living with a Fontan circulation in 11 countries across the US, Europe, Australia and New Zealand, by procedure type: [atriopulmonary connection (AP), lateral tunnel total cavopulmonary connection (LT-TCPC) or extracardiac total cavopulmonary connection (EC-TCPC)]; and age group: [children ( $<12$ years), adolescents (12-17 years), and adults ( $\geq 18$ years old)] by building an epidemiologic model.

Methods: The annual number of Fontan surgeries by country in 2010-2020 were extracted from hospital or claims databases, via procedure

Supplementary Information The online version contains supplementary material available at https:// doi.org/10.1007/s12325-021-02002-3.

L. Plappert · A. De Martini

Charles River Associates, Zürich, Switzerland

S. Edwards $(\bowtie) \cdot A$. Senatore

Janssen Actelion Pharmaceuticals Ltd., Allschwil,

Switzerland

e-mail: SEdwar10@ITS.JNJ.com codes. The epidemiology of persons living with Fontan was modelled by applying these surgery frequencies to mid-year populations from 1972 to 2020 and overlaying an uptake curve. A literature search identified: 30-day mortality rates, long-term survival, and median age at surgery. Averages of these estimates were inputted into the model to project prevalence in 2030 .

Results: The number of persons living with Fontan in 2020 across the 11 countries was estimated to be 47,881 [ 66 people per million (ppm)], rising to 59,777 (79 ppm) by 2030 . In 2020 , this population was $55 \%$ adults, $17 \%$ adolescents and $28 \%$ children shifting to $64 \%$, $13 \%$ and $23 \%$, respectively, in 2030 . Among all persons living with Fontan, $74 \% / 18 \% / 9 \%$ are estimated to have EC-TCPC/LT-TCPC/AP, respectively, in 2020, and $83 \% / 14 \% / 4 \%$ in 2030.

Conclusions: According to this epidemiology model, the Fontan population is growing, partly driven by increased survival rates with the more recent LT-TCPC and EC-TCPC procedures (compared with AP). The 2020/2030 prevalence of persons living with Fontan is $66 / 79 \mathrm{ppm}$.

Keywords: Atriopulmonary connection [AP]; Epidemiology; Extracardiac total cavopulmonary connection [EC-TCPC]); Fontan; Lateral tunnel total cavopulmonary connection [LT-TCPC]; Prevalence; Univentricular heart 


\section{Key Summary Points}

Why carry out this study?

Fontan surgery is a palliative procedure performed in children with a functionally univentricular heart.

Advances in surgical technique have substantially improved survival rates and patient outcomes; however, data on longterm survival and epidemiology are lacking for this rare condition.

\section{What was the hypothesis of the study?}

This study aimed to develop an epidemiologic model to estimate the prevalence of Fontan-palliated persons across 11 countries (Australia, New Zealand, Sweden, Switzerland, Netherlands, Germany, Italy, Spain, France, UK and USA) in 2020 and project estimates for 2030.

\section{What were the study outcomes and conclusions?}

The number of Fontan-palliated persons across the 11 countries was 47,881 in 2020 , corresponding to a prevalence of 66 people per million (ppm) and, by 2030 , this population is expected to rise to 59,777 (79 ppm). Among all persons living with Fontan, the share of those with extracardiac total cavopulmonary connection (EC-TCPC) is predicted to rise from $74 \%$ in 2020 to $83 \%$ in 2030 . The proportion of adults is expected to rise from 55 to $64 \%$ over the same time period.

\section{What was learned from the study?}

This study collates existing evidence to provide a novel perspective on the epidemiology of persons living with Fontan.
In this epidemiology model, the proportion of adults living with Fontan is growing, as is the whole population of Fontan. In this model, these changes are driven by the growth in the general population, together with better survival rates with TCPC procedures (compared with the earlier form of Fontan surgery). As a result, our model indicates an increasing need for healthcare support in this rare population.

\section{INTRODUCTION}

Approximately 1 in 10,000 infants are born with a univentricular heart [1] and are unlikely to survive into adulthood without the palliative Fontan procedure $[1,2]$. In the modern era, the Fontan operation is the final operation of a staged surgical process (at least two major cardiovascular surgeries) conducted to achieve a Fontan circulation. Norwood is performed on infants in the first few weeks of life, followed by Glenn surgery at the age of around 4-6 months and, finally, the Fontan procedure is commonly performed in infants between the ages of 2 and 4 years [3-7]. As a result of the surgery series, both superior and inferior venae cavae are rewired so that venous return is routed directly to the pulmonary artery, bypassing the heart, thus preventing oxygenated and deoxygenated blood from mixing in the single ventricle [8].

Although the principles of Fontan surgery have remained unchanged over the past few decades, the Fontan technique has been modified since the original procedure. Thus, there are three types of Fontan procedure: atriopulmonary connection (AP), lateral tunnel total cavopulmonary connection (LT-TCPC), and extracardiac total cavopulmonary connection (EC-TCPC). These procedures were first described in 1971 [9], 1983 [10, 11] and 1988 [11, 12], respectively. Over time, TCPC procedures have superseded the original AP surgery [13], becoming more common in the 1990s [14, 15], due to the improved survival rates with TCPC procedures [13, 16-19]. In the early surgical era 
(1973-1990), the 10-year survival rate was 69\% [19], improving to $89 \%$ by $1991-2000$ and reaching $95 \%$ by 2001 onwards [19]. There is a surgical preference for EC-TCPC in several clinics $[20,21]$, based on studies indicating a lower incidence of adverse events (such as arrhythmias) following surgery [19-22]. However, nearly half of all Fontan survivors experience major adverse events in the years following the procedure [23]. Further long-term outcome data would be valuable to fully understand the impact of the latest procedure modifications $[13,20]$. Importantly, robust data are lacking on the current epidemiology of persons living with Fontan.

This study aimed to develop an epidemiologic model to estimate the prevalence of persons living with Fontan in 11 countries (Australia, New Zealand, Sweden, Switzerland, Netherlands, Germany, Italy, Spain, France, UK and USA). The prevalence was estimated for 2020 and extrapolated through to 2030, with stratification of prevalence estimates by procedure type (AP, LT-TCPC and EC-TCPC) and age group ( $<12$ years, $12-17$ years and $\geq 18$ years old).

\section{METHODS}

\section{Study Design}

\section{Overview of Epidemiology Model}

A schematic overview of the study epidemiologic model is shown in Figure S1. The model was built in Microsoft Excel. Mid-year population estimates for each country were taken from the US Census Bureau [24]. The model was created using the following steps, which were conducted or calculated for each country. First, the annual number of Fontan procedural codes for the most recent 5 years available were extracted from hospital or claims databases and averaged to give a single estimate for the 2010-2020 period. Second, the frequency of surgery conducted in last 5 years by country was applied to mid-year populations since 1972 . And third, an uptake curve for the Fontan procedure (overall) and subtype utilisation curves were modelled and used to adjust the annual numbers of AP, LT-TCPC and EC-TCPC Fontan surgeries since 1972. A literature search was conducted to determine survival rates and the median age at Fontan surgery for each Fontan procedure type. Long-term (30-year) survival curves for each procedure type were generated and used to estimate the number of patients alive in 2020. The median age at which Fontan procedure types occurred was then applied to stratify this prevalence estimate by age cohort. The prevalence estimates were then extrapolated through to 2030.

1. Estimation of the number of Fontan procedures conducted annually between 1972 and 2020

1.1 Extraction of Fontan procedural codes from databases for the 2010-2020 period

The number of Fontan procedures conducted annually was estimated by extracting the most recent 5 years of available data (between 2010 and 2020) of Fontan procedure codes from a claims or administrative database for each of the countries except Australia and New Zealand. For Australia and New Zealand, the number of procedures were taken from the binational registry [14]. Data for these two countries were grouped together throughout the above-outlined steps.

Procedure codes for all three types of Fontan surgeries (AP, LT-TCPC and EC-TCPC) were extracted from the available claims or hospital databases, with hospital databases being the preferred data source. Table S1 summarises the databases and the procedure codes used. For example, a US claims database, the COMPILE database, was used to extract procedure codes for the US. Data for the most recent 5 years available (over the 2010-2020 period) were extracted and entered into the model (Table S1). Wherever possible, the procedure counts were checked against another hospital or claims database. For example, procedure counts from the US COMPILE database were cross-checked against reports from the National Inpatient Sample (NIS) by Akintoye et al. [25] (Table S1).

1.2 Application of the uptake curve to estimate the number of Fontan procedures occurring prior to 2010 
The extracted procedure counts (Sect. 1.1) were converted to procedure rates (defined as number of procedures per 100,000 inhabitants per year). These procedure rates were applied to their respective national populations between 1972 and 2020. To account for (1) gradual uptake or implementation of Fontan surgery into surgical procedure catalogue of national healthcare institutions and (2) utilisation of different procedure types between 1972 and 2020; a Fontan uptake curve was created and applied (Figure S2). This uptake curve was modelled based predominantly on data from The Australia and New Zealand Fontan Registry, and it assumed a slow initial uptake of the procedure as surgery teams developed more experience with the procedure [26]. The uptake curve plateaued by 2001 and therefore the average rate of procedures after this point was assumed to represent 100\% uptake for Fontan surgeries. In other words, there was no capacity constraint to conduct Fontan surgeries in any country. Using this assumption, the curve was applied to adjust and estimate the average procedure rates in each country between 1972 and 2010.

1.3 Applying subtype utilisation curves to obtain the average annual number of AP, LT-TCPC and EC-TCPC procedures

Subtype utilisation curves were developed to model the uptake of each of the procedure types, within this overall rate of uptake. These curves were modelled based on data from The Australia and New Zealand Fontan Registry and the systematic literature review by Kverneland et al. [26] (Figure S3). They were applied to the annual number of overall conducted Fontan procedures by year and country since 1972 to yield annual procedure numbers for AP, LT-TCPC and EC-TCPC by year and country.

\section{Literature search}

A comprehensive literature search was conducted to identify published estimates of the following parameters (all split by procedure type): median age at Fontan procedure, 30-day mortality rates and long-term survival rates (10, 15, 20, 25, 30 and 35-years post-Fontan).

PubMed was searched in December 2020 for relevant articles published at any time, with a focus on those from the last 5 years. The following search terms for the title or abstract were used: 'mortality' or 'survival' and 'fontan' or 'TCPC' or 'total cavopulmonary anastomosis' and 'long term' or 'long-term' or 'intermediate' and 'outcome' or 'result' or 'prognosis'. The literature search results were filtered to exclude non-human studies, articles not written in the English language and those without abstract or full-text available. Duplicate records were also removed. The remaining articles were reviewed and excluded if: (1) data were not based on any of the 11 countries included in this study, (2) the study sample size was low $(n<100$ participants), (3) methodology was unclear and unable to be reproduced, (4) the study was specific to a narrow subset of patients which may not be representative (e.g. a focus on patients with specific aetiology or only adult patients) (5) if the reported data had a wide variance, (6) if data were outdated (prior to 2000), or (7) if the study author indicated a high degree of uncertainty.

For each of the parameters, an average was calculated from all published estimates. These averages were assumed to apply to all 11 countries, as healthcare systems are similarly developed across these countries and country-specific data were scarce in the literature.

3. Calculation of Fontan prevalence overall and by age and subtype categories, using data derived from literature search

Survival curves for the procedure subtypes were created (based on literature-derived survival rates) and used to calculate prevalence of persons living with Fontan. The survival curves (Figure S4) were created using 30-day mortality after the last Fontan surgery as the input for timepoint 0 (i.e. for a procedure type with a 30 -day mortality of $10 \%$, the survival curve began at $90 \%$ at timepoint 0) (Figure S4). Between timepoint 0 , and the first year of input from the literature (10 years post-Fontan), a linear decrease in survival was assumed. This assumption was also applicable between the other years of literature input (for example, between 10 and 15 years post-Fontan). Beyond the last year of input from the literature, a yearon-year decrease in survival of $1.25 \%$ was 
assumed. This decrease is similar to the year-onyear mortality for a general population, and is also in line with reports of a constant 1.3\% mortality rate per year beyond 20 years postFontan from Dabal et al. [27]. These survival curves (Figure S4) were applied to the number of AP, LT-TCPC and EC-TCPC patients between 1972 and 2020 to yield prevalence estimates. The average age of patients at time of surgery (by procedure type) was then applied to estimate the prevalence split by age group.

4. Verification of the model's outputs

Wherever possible, the model outputs were cross-checked with a second or multiple other sources from that country. Published real-world data on Fontan prevalence were available from two studies from Australia and New Zealand (Schilling et al. [14], Iyengar et al. [28]) and from one study from Sweden (Dahlqvist et al. [29]). These results were compared with the estimates from our model to determine whether our data were consistent with the available literature.

5. Projection to 2030

The epidemiology model was used to extrapolate the prevalence of Fontan through to 2030. In order to project this information, US census bureau projections of population size were used and stable procedure rates between 2020 and 2030 were assumed. In addition, we assumed that factors such as access to care and proportion of pregnancy terminations remained stable.

\section{Statement of Ethics Compliance}

This study was conducted in accordance with ethical principles of the Declaration of Helsinki and Good Clinical Practice guidelines. This study did not require informed consent or institutional/ethical review board approval as this study is a non-interventional study based on secondary data use. All aggregated patient data used were compliant with the Health Insurance Portability and Accountability Act of 1996.

\section{RESULTS}

\section{Model Inputs}

\section{Fontan Procedure Counts}

The average number of Fontan procedures reported annually for the 2010-2020 period was 59 for Australia and New Zealand, 18 for Switzerland, 219 for Germany, 53 for Spain, 86 for France, 27 for the Netherlands, 21 for Sweden, 170 for the UK and 1024 for the USA. This corresponds to an average annual number of Fontan procedures per 100,000 individuals of 0.19 (Australia and New Zealand), 0.21 (Switzerland), 0.27 (Germany), 0.11 (Spain); 0.13 (France); 0.16 (Netherlands); 0.21 (Sweden); 0.26 (UK) and 0.31 (USA). As there were no data available for Italy, it was assumed that the average annual number of procedures reported per 100,000 individuals was the same as for Spain (0.11 per 100,000$)$. These data are presented by country in Table $\mathrm{S} 2$.

\section{Literature Search}

A total of 20 references were identified that reported at least one of the following parameters (all split by procedure type): median age at Fontan surgery, 30-day mortality rate, or longterm survival ( $\geq 10$ years post-Fontan). Creation of an average for each parameter yielded the summary estimates shown in Table 1.

The 30-day mortality rate during the initial hospital stay was lower with EC-TCPC (1.9\%), compared with LT-TCPC (6.6\%) and AP $(11.5 \%)$, and long-term survival rates were highest for EC-TCPC and lowest following AP procedures (Table 1). Although data were available for the 30-year survival rates postFontan for the AP (48.5\%) and LT-TCPC (59.8\%) procedures, there were no robust estimates for the EC-TCPC procedure that met the inclusion criteria. For example, Pundi et al. [19] reported a 30 -year survival rate of $60 \%(n=120)$ for EC-TCPC procedures; however, this information was not included due to the study focus on younger persons with a higher proportion of fenestrations. Therefore, the model assumes a 30 -year survival of $80 \%$ for the EC-TCPC procedure, based on a $1.25 \%$ year-on-year decrease 
Table 1 Data from the literature used as an input for the epidemiologic model

\begin{tabular}{|c|c|c|c|}
\hline \multirow[t]{2}{*}{ Characteristic } & \multicolumn{3}{|c|}{ Fontan type } \\
\hline & $\overline{\mathrm{AP}}$ & LT-TCPC & EC-TCPC \\
\hline 30-day mortality rate ${ }^{a}, \%$ & 11.5 & 6.6 & 1.9 \\
\hline 10 -year long-term survival rate ${ }^{\mathrm{b}}, \%$ & 81.0 & 90.3 & 93.6 \\
\hline 20-year long-term survival rate ${ }^{c}, \%$ & 74.3 & 87.9 & 93.0 \\
\hline 30-year long-term survival rate ${ }^{\mathrm{d}}, \%$ & 48.5 & 59.8 & $\mathrm{n} / \mathrm{a}$ \\
\hline Age at Fontan ${ }^{\mathrm{e}}$, median years & 6.2 & 3.75 & 4.3 \\
\hline
\end{tabular}

Numbers are unweighted averages of all selected sources, e.g. 10-year mortality for LT is an unweighted average of values given in papers from Ali 2018 [11], Pundi 2015 [19], van den Bosch 2019 [36]

$A P$ atriopulmonary connection, $E C-T C P C$ extracardiac total cavopulmonary connection, $L T-T C P C$ lateral tunnel total cavopulmonary connection

${ }^{a}$ Data sources were: Akintoye 2018 [25], Alphonso 2005 [37], Brown 2010 [38], d'Udekem 2014 [23], Giannico 2006 [39], Iyengar 2014 (A) [28], Iyengar 2014 (B) [40], Jacobs 2018 [41], Pundi 2015 [19], Rogers 2012 [20], Rijnberg 2019 [42], Wilson 2017 [43]

${ }^{b}$ Data sources were: Ali 2018 [11], Dabal 2014 [27], d'Udekem 2014 [44], Giannico 2006 [39], Khairy 2008 [30], Ono 2006 [45], Pundi 2015 [19], van den Bosch 2019 [36]

'Data sources were: Ali 2018 [11], d’Udekem 2014 [44], Elder 2015 [31], Khairy 2008 [30], Poh 2017 [46], Pundi 2015 [19], Rijnberg 2019 [42]

${ }^{\mathrm{d}}$ Data sources were: Elder 2015 [31], Pundi 2015 [19], Rijnberg 2019 [42]

${ }^{\mathrm{e}}$ Data sources were: Dennis 2018 [47], Iyengar 2014 [40], Poh 2017 [46], Rijnberg 2019 [42], van den Bosch 2019 [36]

beyond the 25-year timepoint (the last timepoint for which an estimate could be derived from the literature).

\section{Model outputs}

\section{Prevalence of Fontan}

In 2020, the number of people living with a Fontan circuit across the 11 countries included in the study was estimated to be 47,881 , according to the epidemiology model. Of these, 27,401 people were in the US, 19,017 in Europe and 1463 in Australia and New Zealand (Table S3A). Overall, this corresponds to point prevalence estimates of 66 people per million (ppm) across the 11 countries: $82.4 \mathrm{ppm}$ in the USA, $52.7 \mathrm{ppm}$ across Europe and $48.2 \mathrm{ppm}$ in Australia and New Zealand. By 2030, the number of people who are living with Fontan across the 11 countries is projected to increase to 59,777 , corresponding to a point prevalence of $79 \mathrm{ppm}$. This growth is based on general population growth, improved survival with TCPC procedures versus AP and it assumes that factors such as access to care and incidence of pregnancy terminations are as for 2020. The prevalence estimates are shown by country, age group and procedural subtype for 2020 and 2030 in Table S3.

\section{Age Group of Fontan-Palliated Persons}

In 2020, the Fontan population is estimated to be comprised of $55 \%$ adults ( $\geq 18$-year olds), $17 \%$ adolescents (12 to 17 -year olds) and $28 \%$ children $(<12$ years old), shifting to $64 \%$ adults, $13 \%$ adolescents and $23 \%$ children by 2030 (Fig. 1). The number of persons living with Fontan in 2010-2020 stratified by age group is shown in Figure S5.

\section{Procedural Type of Fontan-Palliated Persons}

Between 2010 and 2020, EC-TCPC was the most common procedure type among persons living with Fontan (Figs. 2A, 3) and this is expected to remain the same, through 2030 (Figs. 2B, 3). By 2030 , the share of persons alive by procedure type is predicted to be $83 \%$ for EC-TCPC, $14 \%$ for LT-TCPC and $4 \%$ for AP (Fig. 3). In this 


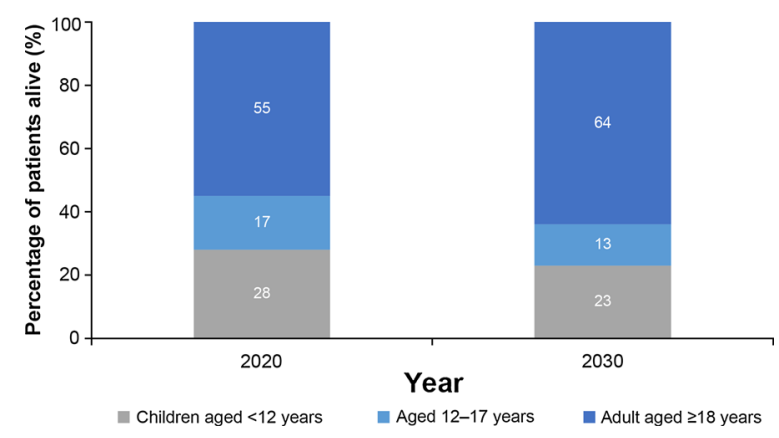

Fig. 1 Proportion of people alive in 2020 compared with projections for 2030, by age group; results from the epidemiology model model, these changes are driven by an increasing use of EC-TCPC procedures and the retiring of the AP procedure.

\section{Verification of the Model's Outputs}

This model estimated that 1239 people were living with Fontan in Australia and New Zealand in 2014, compared with 1265 reported by a previous publication from The Australia and New Zealand Fontan Registry [14]. The distribution of procedure types were also similar for this model versus estimates for 2014 reported by

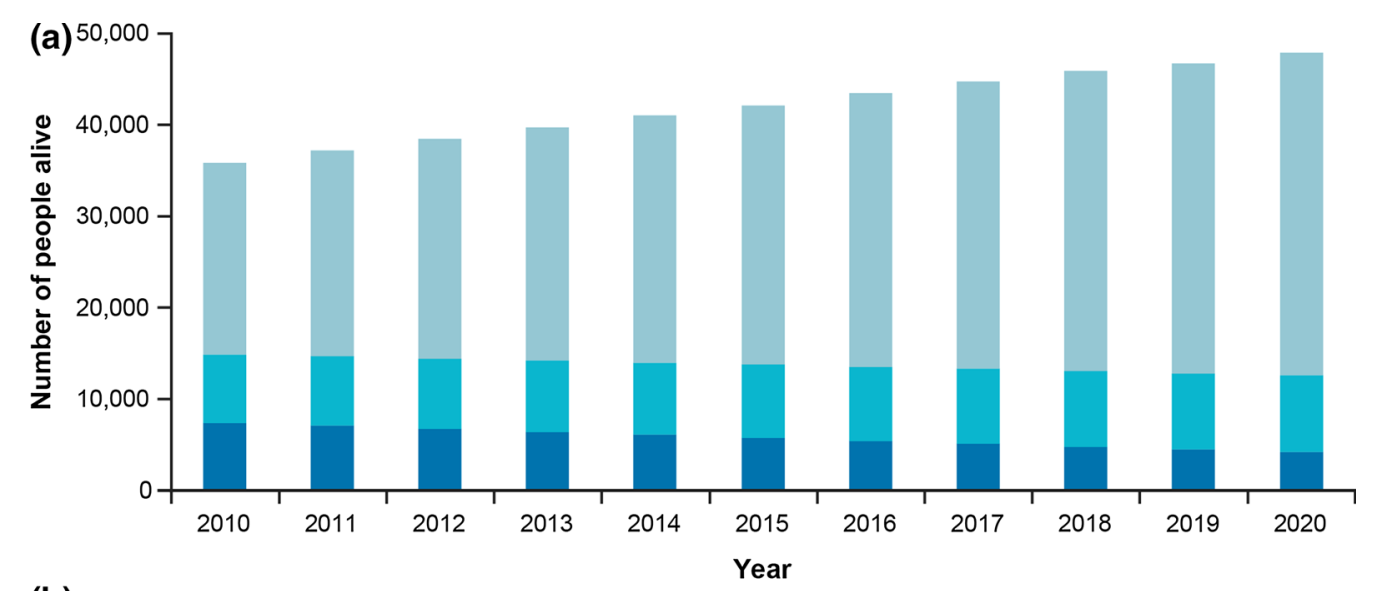

(b)

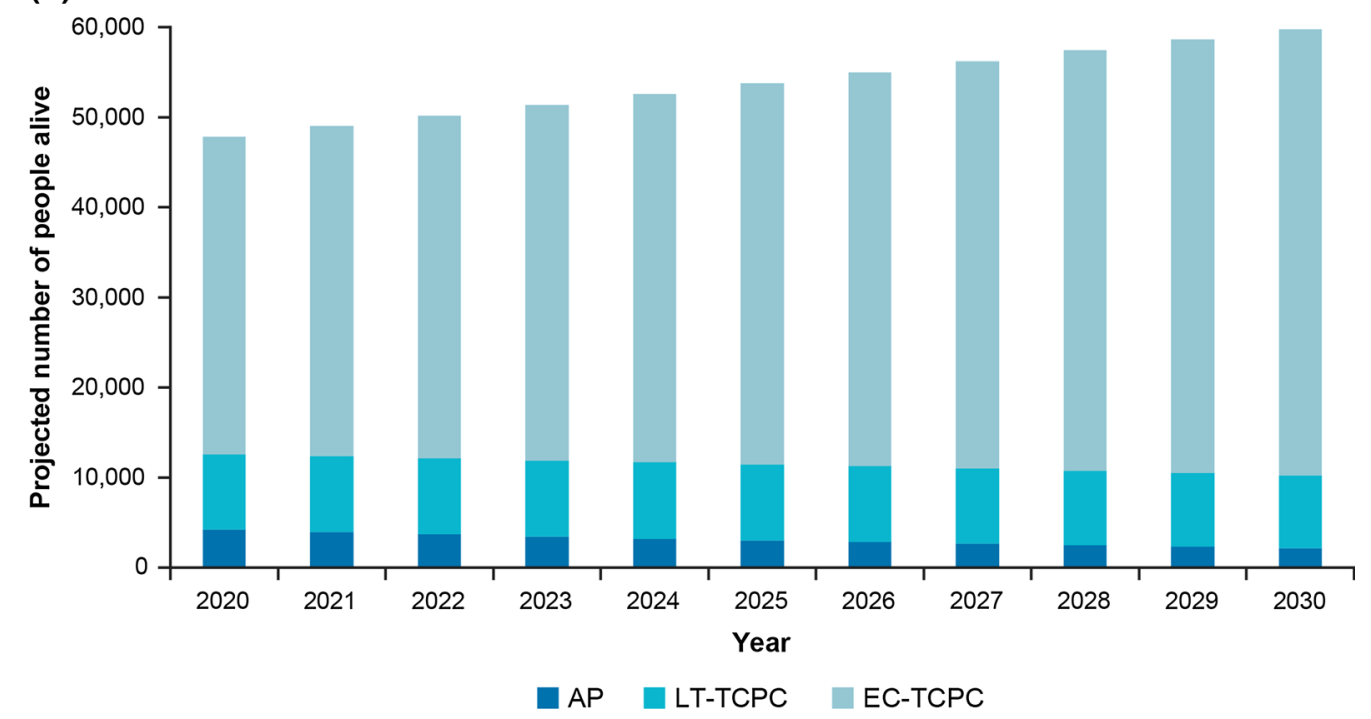

Fig. 2 Estimates of the number of people alive with a Fontan circuit in A 2010-2020 and projection through B 2020-2030, by procedural subtype. $A P$ atriopulmonary connection, $E C-T C P C$ extracardiac total cavopulmonary connection, $L T-T C P C$ lateral tunnel total cavopulmonary connection 


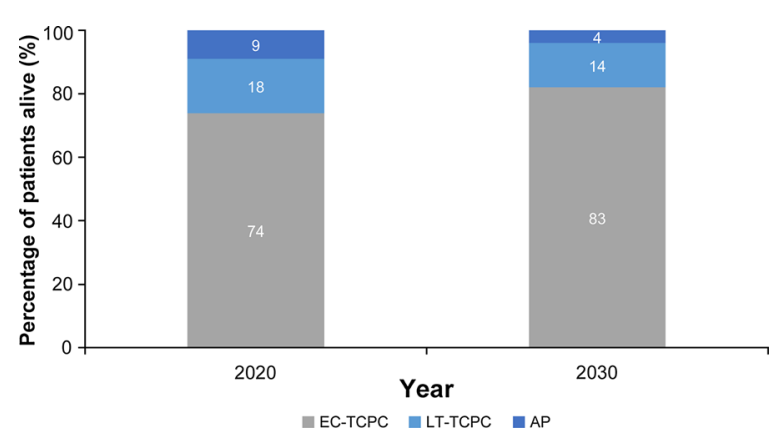

Fig. 3 Proportion of people alive by Fontan procedural subtype in 2020 compared with 2030; results from the epidemiology model; percentages do not total to 100 due to rounding. $A P$ atriopulmonary connection, EC-TCPC extracardiac total cavopulmonary connection, $L T-T C P C$ lateral tunnel total cavopulmonary connection

Schilling et al. [14]: 13\% versus 13\% for AP, 19\% versus $21 \%$ for LT-TCPC and $68 \%$ versus $66 \%$ for EC-TCPC. Furthermore, according to our model, 556 people in this region underwent EC-TCPC between 1997 and 2010, and the number reported for the registry by Iyengar et al. [28] is 570. However, it should be noted that some of our model inputs (uptake curves and Australia-New Zealand source data) were based on The Australia and New Zealand Fontan Registry [14]. For Sweden, this model found that 618 people received Fontan surgery between 1982 and 2017, whereas a retrospective Swedish national study reported this number to be 599 people [29].

\section{DISCUSSION}

This epidemiology model was created to fill a gap in knowledge on the epidemiology of Fontan. Estimates for the numbers of children born with a single ventricle heart are available in the literature, but it is not possible to use these as epidemiology estimates, as not all patients will undergo Fontan surgery or survive the Fontan procedures. Most studies published to date are small and/or based on a single centre and therefore cannot be relied upon for robust epidemiology estimates [20, 30, 31]. Our model estimated the prevalence of persons living with Fontan across the 11 included countries to be $66 \mathrm{ppm}$ in 2020, rising to $79 \mathrm{ppm}$ in 2030 . In addition, our model estimated that the Fontan population would become increasingly older (55\% adults in 2020 , rising to $64 \%$ in 2030 ) and that the proportion of persons living with an EC-TCPC procedure type would also increase (74-83\%). This model has collated the largest set of multinational data on Fontan epidemiology, and represents the only set of multicontinental data, to our knowledge. As such, this model provides novel insights into the epidemiology of persons living with Fontan.

Our model suggests that the number of persons living with Fontan is likely to continue to grow. The projected growth in our model was driven by increased survival due to TCPC procedures, particularly with EC-TCPC, compared with earlier forms of Fontan [17-19] and the projected growth in general population size (with the exception of Germany, where population size is in decline). In turn, the model also provided evidence of an ageing Fontan population, as more patients survive into adulthood. This is consistent with another study of Fontan epidemiology: Schilling et al. [14] estimated the prevalence of persons living with Fontan in Australia and New Zealand to be $45 \mathrm{ppm}$ in 2014, rising to $58 \mathrm{ppm}$ in 2025 and $72 \mathrm{ppm}$ in 2045 , with the average age of the Fontan population increasing from 18 to 31 years over the same time period. They projected prevalence probabilistically using a microsimulation method and robust data from the long-term Australia and New Zealand registry. Their model also considered more factors relating to survival such as gender and morphology (hypoplastic left-heart syndrome versus other) compared with ours. Our model supports these findings of a growing, ageing Fontan population and suggests this trend applies globally. Therefore, the healthcare support needs of this rare population could increase in future.

Our model is based on survival estimates taken from the literature, and the results of our literature search further demonstrate the scarcity of data available on the long-term survival with Fontan surgery. This is particularly true for the EC-TCPC procedure. Thirty-year survival rates were not available in the literature for EC-TCPC, due to the relatively recent availability of this procedure. It is reassuring that the 
survival curves generated and used in this model predicted a 30-year survival rate for EC-TCPC $(80 \%)$ that is in line with the expectations for 30-year survival with EC-TCPC noted in the Scientific Statement from the American Heart Association [4]. However, further research is needed to confirm if the long-term survival rates with EC-TCPC are accurate.

This study has several limitations. The average number of annual Fontan procedures for the 2010-2020 period was based on the five most recent years with data available. Therefore, projections both forwards and backwards in time were based on assumptions and potential fluctuations in trends may not have been adequately captured. There could be fluctuation in the incidence of pregnancy terminations, for example, and improvements in the biventricular repair technique [32-35] may lead to some decline in the number of Fontan surgeries conducted in future. However, we have assumed a steady rate of Fontan and these potential trends would therefore not be captured. It is also unlikely that the databases used to extract Fontan procedure codes have captured all clinically relevant cases of Fontan. In addition, our model did not account for further interventions, such as conversion of Fontan circulation (AP to TCPC), Fontan takedown or heart transplantation, or for the potential for differences in model parameters to be driven by the type of congenital heart defect. It is also important to highlight that the model cannot be used to provide country-specific estimates, as there were not enough country-specific data to populate the model. Instead, the prevalence estimates are 'global' across the 11 included countries.

Our model's key strength is that it involves collection of the strongest existing evidence of Fontan epidemiology and therefore represents the largest set of data available. Another strength is that the model inputs and outputs were cross-checked with other sources at several stages. For example, the procedure counts extracted from the US COMPILE database were relatively consistent with those reported from the NIS by Akintoye et al. [25], suggesting that the retrieved data are reliable. Moreover, the model's prevalence outputs were cross-checked with other estimates available in the literature, finding only slight difference between our estimates and those of Schilling et al. [14], Iyengar et al. [28] (both on the Australia and New Zealand registry) and Dahlqvist et al. [29] (Sweden). However, the similarity between our models estimates and those reported by Schilling et al., and Iyengar et al., are expected, given that our model used this registry as the source of the Australia-New Zealand procedure counts and as the basis for creating the uptake curve. Nevertheless, it is reassuring that there are no large differences between our model's estimates and published estimates of Fontan prevalence in Sweden, Australia and New Zealand.

\section{CONCLUSION}

Our epidemiologic model collates existing evidence from 11 countries across Europe, USA, Australia and New Zealand and provides a novel overview of the epidemiology of persons living with Fontan. Our model indicates that there is a growing and ageing population of persons living with Fontan, with prevalence predicted to increase from 66 to $79 \mathrm{ppm}$ between 2020 and 2030 , and the proportion of adults rising from 55 to $64 \%$ over the same period. In our model, these changes were driven by the better survival rates with TCPC versus $\mathrm{AP}$, the increasing preference for EC-TCPC and the predicted growth in general population size.

\section{ACKNOWLEDGEMENTS}

Funding. Charles River Associates received funding from Actelion Pharmaceuticals Ltd, a Janssen Pharmaceutical Company of Johnson \& Johnson for the design and completion of this study. The journal's Rapid Service and Open Access fees were funded by Actelion Pharmaceuticals Ltd., a Janssen Pharmaceutical company of Johnson \& Johnson.

Medical writing assistance. Medical writing support was provided by Emily Evans and Richard McDonald of Ashfield MedComms, an Ashfield Health company, and funded by 
Actelion Pharmaceuticals Ltd, a Janssen Pharmaceutical Company of Johnson \& Johnson.

Authorship. All named authors meet the International Committee of Medical Journal Editors (ICMJE) criteria for authorship for this article, take responsibility for the integrity of the work as a whole, and have given their approval for this version to be published.

Author contributions. All authors contributed to the study conception and design. Data collection and data analyses were performed by Leandra Plappert and Angela De Martini. All authors contributed to the interpretation of data. All authors critically revised each draft and read and approved the final manuscript.

Disclosures. Susan Edwards and Assunta Senatore are employees of Actelion Pharmaceuticals Ltd, a Janssen Pharmaceutical Company of Johnson \& Johnson. Leandra Plappert and Angela De Martini are employees of Charles River associates and were contracted by Actelion Pharmaceuticals Ltd, a Janssen Pharmaceutical Company of Johnson \& Johnson to complete this study.

Compliance with Ethics Guidelines. This study was conducted in accordance with ethical principles of the Declaration of Helsinki and Good Clinical Practice guidelines. This study did not require informed consent or institutional/ethical review board approval as this study is a non-interventional study based on secondary data use. All aggregated patient data used were compliant with the Health Insurance Portability and Accountability Act of 1996.

Data availability. The datasets generated during and/or analysed during the current study are available from the corresponding author on reasonable request.

Open Access. This article is licensed under a Creative Commons Attribution-NonCommercial 4.0 International License, which permits any non-commercial use, sharing, adaptation, distribution and reproduction in any medium or format, as long as you give appropriate credit to the original author(s) and the source, provide a link to the Creative Commons licence, and indicate if changes were made. The images or other third party material in this article are included in the article's Creative Commons licence, unless indicated otherwise in a credit line to the material. If material is not included in the article's Creative Commons licence and your intended use is not permitted by statutory regulation or exceeds the permitted use, you will need to obtain permission directly from the copyright holder. To view a copy of this licence, visit http://creativecommons.org/licenses/by$\mathrm{nc} / 4.0 /$.

\section{REFERENCES}

1. Clift P, Celermajer D. Managing adult Fontan patients: where do we stand? Eur Respir Rev. 2016;25:438-50.

2. Moodie DS, Ritter DG, Tajik AJ, O'Fallon WM. Long-term follow-up in the unoperated univentricular heart. Am J Cardiol. 1984;53:1124-8.

3. Kritzmire SM, Cossu AE. Hypoplastic Left Heart Syndrome. In: (FL) TI, editor. StatPearls [Internet]: StatPearls Publishing; 2021.

4. Rychik J, Atz AM, Celermajer DS, Deal BJ, Gatzoulis MA, Gewillig MH, et al. Evaluation and management of the child and adult with Fontan circulation: a scientific statement from the American Heart Association. Circulation. 2019;140:e234-84.

5. Daley M, d'Udekem Y. In patients undergoing Fontan completion, does a younger age at operation result in better long-term exercise capacity and prognosis? Interact Cardiovasc Thorac Surg. 2018;28:301-5.

6. Kaulitz R, Hofbeck M. Current treatment and prognosis in children with functionally univentricular hearts. Arch Dis Childhood. 2005;90: 757-62.

7. Akintoye E, Veldtman GR, Miranda WR, Connolly HM, Egbe AC. Optimum age for performing Fontan operation in patients with univentricular heart. Congenit Heart Dis. 2019;14:138-9.

8. van der Ven J, van den Bosch E, Bogers A, Helbing W. State of the art of the Fontan strategy for 
treatment of univentricular heart disease [version 1; peer review: 2 approved]. F1000Research. 2018;7:1.

9. Fontan F, Baudet E. Surgical repair of tricuspid atresia. Thorax. 1971;26:240-8.

10. de Leval MR, Kilner P, Gewillig M, Bull C. Total cavopulmonary connection: a logical alternative to atriopulmonary connection for complex Fontan operations. Experimental studies and early clinical experience. J Thorac Cardiovasc Surg. 1988;96: 682-95.

11. Ben Ali W, Bouhout I, Khairy P, Bouchard D, Poirier N. Extracardiac versus lateral tunnel Fontan: a meta-analysis of long-term results. Ann Thorac Surg. 2019;107:837-43.

12. Marcelletti C, Corno A, Giannico S, Marino B. Inferior vena cava-pulmonary artery extracardiac conduit. A new form of right heart bypass. J Thorac Cardiovasc Surg. 1990;100:228-32.

13. Goldberg DJ. The Fontan operation: improved outcomes, uncertain future. J Am Coll Cardiol. 2015;66:1711-3.

14. Schilling C, Dalziel K, Nunn R, Du Plessis K, Shi WY, Celermajer D, et al. The Fontan epidemic: population projections from the Australia and New Zealand Fontan Registry. Int J Cardiol. 2016;219:14-9.

15. Downing TE, Allen KY, Goldberg DJ, Rogers LS, Ravishankar C, Rychik J, et al. Surgical and catheterbased reinterventions are common in long-term survivors of the Fontan operation. Circ Cardiovasc Interv. 2017;10:e04924.

16. Hosein RBM, Clarke AJB, McGuirk SP, Griselli M, Stumper O, De Giovanni JV, et al. Factors influencing early and late outcome following the Fontan procedure in the current era. The 'Two Commandments.' Eur J Cardio-Thorac Surg. 2007;31:344-53.

17. Becker RC. Anticipating the long-term cardiovascular effects of COVID-19. J Thromb Thrombol. 2020;50:512-24.

18. Tweddell JS, Nersesian M, Mussatto KA, Nugent M, Simpson P, Mitchell ME, et al. Fontan palliation in the modern era: factors impacting mortality and morbidity. Ann Thorac Surg. 2009;88:1291-9.

19. Pundi KN, Johnson JN, Dearani JA, Pundi KN, Li Z, Hinck CA, et al. 40-year follow-up after the Fontan operation: long-term outcomes of 1,052 patients. J Am Coll Cardiol. 2015;66:1700-10.

20. Rogers LS, Glatz AC, Ravishankar C, Spray TL, Nicolson SC, Rychik J, et al. 18 years of the Fontan operation at a single institution: results from 771 consecutive patients. J Am Coll Cardiol. 2012;60: 1018-25.

21. Kogon B. Is the extracardiac conduit the preferred Fontan approach for patients with univentricular hearts? Circulation. 2012;126:2511-5.

22. Khairy P, Poirier N. Is the extracardiac conduit the preferred Fontan approach for patients with univentricular hearts? Circulation. 2012;126:2516-25.

23. d'Udekem Y, Iyengar AJ, Galati JC, Forsdick V, Weintraub RG, Wheaton GR, et al. Redefining expectations of long-term survival after the Fontan procedure: twenty-five years of follow-up from the entire population of Australia and New Zealand. Circulation. 2014;130:S32-8.

24. O'Brien JE Jr, Marshall JA, Young AR, Handley KM, Lofland GK. The nonfenestrated extracardiac Fontan procedure: a cohort of 145 patients. Ann Thorac Surg. 2010;89:1815-20.

25. Akintoye E, Miranda WR, Veldtman GR, Connolly HM, Egbe AC. National trends in Fontan operation and in-hospital outcomes in the USA. Heart. 2019;105:708-14.

26. Kverneland LS, Kramer P, Ovroutski S. Five decades of the Fontan operation: a systematic review of international reports on outcomes after univentricular palliation. Congenit Heart Dis. 2018;13: 181-93.

27. Dabal RJ, Kirklin JK, Kukreja M, Brown RN, Cleveland DC, Eddins MC, et al. The modern Fontan operation shows no increase in mortality out to 20 years: a new paradigm. J Thorac Cardiovasc Surg. 2014;148:2517-23.e1.

28. Iyengar AJ, Winlaw DS, Galati JC, Wheaton GR, Gentles TL, Grigg LE, et al. The extracardiac conduit Fontan procedure in Australia and New Zealand: hypoplastic left heart syndrome predicts worse early and late outcomes. Eur J Cardiothorac Surg. 2014;46:465-73 (discussion 473).

29. Alenius Dahlqvist J, Sunnegårdh J, Hanséus K, Strömvall Larsson E, Nygren A, Dalén $M$, et al. Pacemaker treatment after Fontan surgery-a Swedish national study. Congenit Heart Dis. 2019;14:582-9.

30. Khairy P, Fernandes SM, Mayer JE Jr, Triedman JK, Walsh EP, Lock JE, et al. Long-term survival, modes of death, and predictors of mortality in patients with Fontan surgery. Circulation. 2008;117:85-92.

31. Elder RW, McCabe NM, Veledar E, Kogon BE, Jokhadar M, Rodriguez FH III, et al. Risk factors for major adverse events late after Fontan palliation. Congenit Heart Dis. 2015;10:159-68. 
32. Hraska V, Mitchell ME, Woods RK, Frommelt MA. What surgical improvements are needed to prove that anatomic repair is superior to physiologic repair in the majority of patients with corrected transposition of the great arteries? J Thorac Cardiovasc Surg. 2017;154:1019-22.

33. Hraska V, Vergnat $M$, Zartner $P$, Hart C, Suchowerskyj P, Bierbach B, et al. Promising outcome of anatomic correction of corrected transposition of the great arteries. Ann Thorac Surg. 2017;104:650-6.

34. Huang SC. Commentary: choosing complex biventricular repair versus Fontan-the unmet needs. J Thorac Cardiovasc Surg. 2019;158:1171-2.

35. Sun J, Brizard C, Winlaw D, Alphonso N, d'Udekem $\mathrm{Y}$, Eastaugh L, et al. Biventricular repair versus Fontan completion for patients with d- or l-transposition of the great arteries with ventricular septal defect and left ventricular outflow tract obstruction. J Thorac Cardiovasc Surg. 2019;158:1158-67. e1.

36. van den Bosch E, Bossers SSM, Bogers AJJC, Robbers-Visser D, van Dijk APJ, Roos-Hesselink JW, et al. Staged total cavopulmonary connection: serial comparison of intra-atrial lateral tunnel and extracardiac conduit taking account of current surgical adaptations. Interact Cardiovasc Thorac Surg. 2019;29:453-60.

37. Alphonso N, Baghai M, Sundar P, Tulloh R, Austin C, Anderson D. Intermediate-term outcome following the fontan operation: a survival, functional and risk-factor analysis. Eur J Cardiothorac Surg. 2005;28:529-35.

38. Brown JW, Ruzmetov M, Deschner BW, Rodefeld MD, Turrentine MW. Lateral tunnel Fontan in the current era: is it still a good option? Ann Thorac Surg. 2010;89:556-62 (discussion 562-3).

39. Giannico S, Hammad F, Amodeo A, Michielon G, Drago F, Turchetta A, et al. Clinical outcome of 193 extracardiac Fontan patients: the first 15 years. J Am Coll Cardiol. 2006;47:2065-73.
40. Iyengar AJ, Winlaw DS, Galati JC, Celermajer DS, Wheaton GR, Gentles TL, et al. Trends in Fontan surgery and risk factors for early adverse outcomes after Fontan surgery: the Australia and New Zealand Fontan Registry experience. J Thorac Cardiovasc Surg. 2014;148:566-75.

41. Jacobs JP, Mayer JE Jr, Pasquali SK, Hill KD, Overman DM, St Louis JD, et al. The society of thoracic surgeons congenital heart surgery database: 2018 update on outcomes and quality. Ann Thorac Surg. 2018;105:680-9.

42. Rijnberg FM, Blom NA, Sojak V, Bruggemans EF, Kuipers IM, Rammeloo LAJ, et al. A 45-year experience with the Fontan procedure: tachyarrhythmia, an important sign for adverse outcome. Interact Cardiovasc Thorac Surg. 2019;29:461-8.

43. Wilson TG, Shi WY, Iyengar AJ, Winlaw DS, Cordina RL, Wheaton GR, et al. Twenty-five year outcomes of the lateral tunnel Fontan procedure. Semin Thorac Cardiovasc Surg. 2017;29:347-53.

44. d'Udekem Y, Iyengar AJ, Galati JC, Forsdick V, Weintraub RG, Wheaton GR, et al. Redefining expectations of long-term survival after the Fontan procedure: twenty-five years of follow-up from the entire population of Australia and New Zealand. Circulation. 2014;130:S32-8.

45. Ono M, Boethig D, Goerler H, Lange M, WesthoffBleck M, Breymann T. Clinical outcome of patients 20 years after Fontan operation-effect of fenestration on late morbidity. Eur J Cardiothorac Surg. 2006;30:923-9.

46. Poh CL, Zannino D, Weintraub RG, Winlaw DS, Grigg LE, Cordina R, et al. Three decades later: the fate of the population of patients who underwent the atriopulmonary Fontan procedure. Int J Cardiol. 2017;231:99-104.

47. Dennis $\mathrm{M}$, Zannino D, du Plessis $\mathrm{K}$, Bullock A, Disney PJS, Radford DJ, et al. Clinical outcomes in adolescents and adults after the Fontan procedure. J Am Coll Cardiol. 2018;71:1009-17. 